\title{
In Silico Molecular Docking Approch of Some Selected Isolated Phytochemicals from Phyllanthus Emblic Against Breast Cancer
}

\begin{abstract}
Shanta Afrin ${ }^{1}$, Nazim Uddin ${ }^{2}$, Kazi Zahra Mehjabin ${ }^{3}$, Tarannur Kabir Niketa ${ }^{4}$, Fayejun Nesa ${ }^{4}$, Shermin Akther ${ }^{4}$, Sahida Akther ${ }^{4}$, Sajal Chakraborty ${ }^{4}$, Dipannita Chowdhury ${ }^{4}$ and Nasrin Akther*4
\end{abstract}

${ }^{1}$ Chittagong Medical College, Faculty of Medicine, University of Chittagong, Bangladesh

${ }^{2}$ Department of Pharmacy, Southern University, Bangladesh

${ }^{3}$ Department of Pharmacy, North South University, Bangladesh

${ }^{4}$ Department of Pharmacy, BGC Trust University Bangladesh, Bangladesh

Received: 制: October 06, 2018; Published: 制: October 22, 2018

*Corresponding author: Nasrin Akther, Department of Pharmacy, BGC Trust University Bangladesh, Bangladesh

\begin{abstract}
Breast cancer is an increasing public health problem. One of the main causes of breast cancer is estrogen receptor alpha. Over expression of estrogen receptor is seen in number of cases of breast cancer. The aim of this study was to screen out the effective bioactive compounds from Phyllanthus emblica namely 1,1-diphenyl-2-picrylhydrazyl, isocorilagin, kaempferol, kaempferol 3-bita-D-glucopyranoside and quercetin which may be potential inhibitors of estrogen receptor alpha (ER- $\alpha$ ) for searching a drug against the breast cancer. A wide range of docking score found during molecular docking by Schrodinger. Among all the compounds isocorilagin showed best docking score towards estrogen receptor alpha. So, isocorilagin is the best compounds for selective inhibitors of estrogen receptor alpha, as it possessed best value in Molecular docking. Further in vitro and in vivo investigation need to identify estrogen receptor alpha inhibitory activity of isolated compounds from Phyllanthus emblica.
\end{abstract}

Keywords: Breast Cancer; Estrogen Receptor Alpha (ER- $\alpha$ ); Phyllanthus Emblica; Molecular Docking; Isocorilagin

\section{Introduction}

Cancer is a gathering of infections including unusual cell growth. Cancer causing natural exposures incorporate substances, for example, the synthetic concoctions in tobacco smoke, and radiation, for example, UV Rays from the sun all cell development with the possibility to attack or spread to different parts of the body [1]. It is caused by specific changes to genes, the fundamental physical units of inheritance. Genes are orchestrated in long strands of firmly pressed DNA called chromosomes. Cancer causing natural exposures incorporate substances, for example, the synthetic concoctions in tobacco smoke, and radiation, for example, UV Rays from the sun [2-4]. Cancer is a leading cause of death worldwide. It accounted for 8.2 million deaths (around 22\% of all deaths not related to communicable diseases; most recent data from WHO) [5]. Treatment differ as indicated by the sort and phase of the tumor. Most treatment are intended to fit the individual patient's illness. Be that as it may, most medications incorporate no less than one of the accompanying and may incorporate all: medical procedure, chemotherapy, and radiation treatment.
Breast cancer is an expanding medical issue. Breast cancer in women is a noteworthy general medical issue all through the world. It is the most widely recognized cancer among the women in developed and developing nations. It is the guideline reason for death from cancer among women all around. Breast cancer is cancer that creates from breast tissue. Cancer is a gathering of maladies that reason cells in the body to change and develop out of control. Most kinds of cancer cells in the end frame a lump or mass called a tumor and are named after the parts of the body where the tumor begins. The larger part of breast cancer start in the parts of the breast tissue that are comprised of organs for milk production, called lobules, and ducts that associate the lobules to the nipple [69]. Risk factors for creating breast cancer incorporate being female, obesity, absence of physical exercise, drinking alcohol, hormone substitution treatment amid menopause, ionizing radiation, early age at first menstruation, having kids late or not in the least, older age, earlier history of breast cancer, and family history5. Advances in screening and treatment have enhanced survival rates significantly 
since 1989. There are around 3.1 million breast cancer survivors in the United States (U.S.). The possibility of any lady passing on from breast cancer is around 1 of every 37 , or 2.7 percent [10-12].

Phyllanthus emblica is a species of flowering plant of the genus Phyllanthus in the Phyllanthaceae family. It is planted through the deciduous of tropical India, Uttar Pradesh, Tamil Nadu, Rajasthan and Madhya Pradesh. The tree is little to medium in estimate,

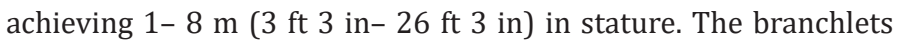
are not glabrous or finely pubescent, $10-20 \mathrm{~cm}$ (3.9- $7.9 \mathrm{in}$ ) long, typically deciduous; the leaves are straightforward, subsessile and firmly set along branchlets, light green, looking like pinnate clears out. The flowers are greenish-yellow. The fruit is about round, light greenish yellow, very smooth and hard on appearance, with six vertical stripes or wrinkles [13-16]. The fruit, seed, leaves, root, bark and flowers are used in various Ayurvedic or Unani herbal preparations. It might be utilized as a rasayana to advance life span, and customarily to improve assimilation, treat constipation, lessen fever, sanitize the blood, decrease cough, mitigate asthma, reinforce the heart, advantage the eyes, fortify hair development, breath life into the body, and upgrade intellect $[16,17]$. Molecular docking is a basic instrument in the change of new prescriptions. Docking procedure grants portraying the direct of a test little molecule in the coupling site of the receptor target of interest.

A productive docking strategy must have the ability to adequately envision the local ligand represent the receptor limiting site (i.e.to find the trial ligand geometry inside a particular resistance confine ) and the related physical-compound submolecular affiliations [18-21].The aim of this study was to screen out the effective bioactive compounds from Phyllanthus emblica, which may be potential inhibitors of estrogen receptor alpha (ER- $\alpha$ ) in future and may act as a drug which may be effective in preventing the breast cancer.

\section{Methods and Materials \\ Protein Preparation}

Three dimensional protein structure of HUMAN ESTROGEN RECEPTOR (PDB id: 3ERT) was downloaded in pdb deal with the protein databank $[22,23]$. Beginning there forward, structure was arranged and refined utilizing the Protein preparation Wizard of Schrödinger-Maestro v10.1. Charges and bond orders were doled out, hydrogens were added to the stunning particles, selenomethionines were changed over to methionines and all waters were killed. Utilizing power field OPLS_2005, minimization was done setting most unprecedented impressive molecule RMSD (root-mean-square-deviation) to $0.30 \AA$.

\section{Ligand Preparation}

Compounds were retrieved from PubChem databases i.e 1,1-diphenyl-2-picrylhydrazyl (CID 2735032), isocorilagin (CID 10077799), kaempferol (CID 5280863), kaempferol 3-bita-Dglucopyranoside (CID 5318761) and quercetin (CID 5280343).

\section{Glide Standard Precision (Sp) Ligand Docking}

SP versatile ligand docking was done in glide of SchrödingerMaestro v10.124,25 inside which disciplines were connected with non-cis/trans amide bonds. Vander Waals scaling variable and fragmentary charge cutoff was being 0.80 and 0.15 , just for ligand particles. Prop up scoring was performed on critically restricted positions and appeared as glide score. The best docked pose with most immaterial glide score regard was recorded for each ligand.

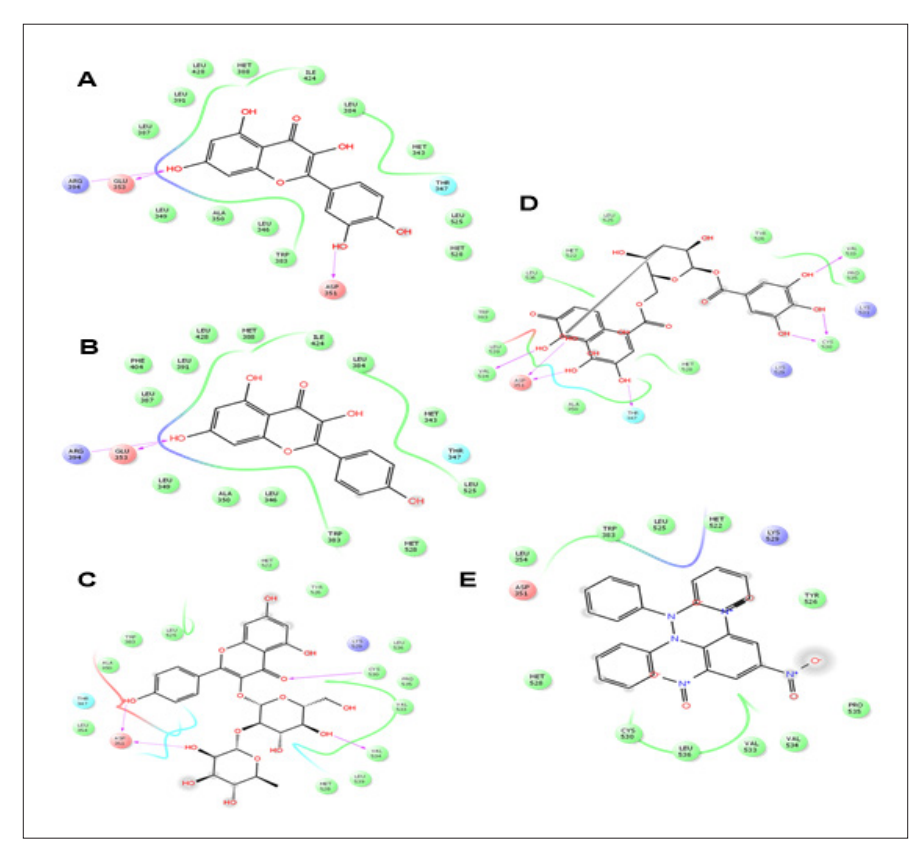

Figure 1: 2D representation of the interactions between the best pose found for quercetin (CID 5280343), kaempferol (CID 5280863), kaempferol 3-bita-D-glucopyranoside (CID 5318761), isocorilagin (CID 10077799) and 1,1-diphenyl-2-picrylhydrazyl (CID 2735032) with estrogen receptor alpha (PDB: 3ERT). 


\section{Result}

\section{In Silico Molecular Docking Analysis}

Advances in computational techniques have enabled virtual screening to have a positive impact on the discovery process. Virtual screening utilizes docking and scoring of each compound from a dataset and the technique used is based on predicting the binding modes and binding affinities of each compound in the dataset by means of docking to an X-ray crystallographic structure [14]. Grid based docking study was used to analyze the binding modes of molecules with the amino acids present in the active pocket of the protein [15] In order to study the interaction of the compounds, like quercetin (CID 5280343), kaempferol (CID 5280863), kaempferol 3-bita-D-glucopyranoside (CID 5318761), isocorilagin (CID 10077799) and 1,1-diphenyl-2-picrylhydrazyl (CID 2735032), with estrogen receptor alpha (ER- $\alpha$ ). We performed Glide docking analysis by Schrodinger suite v10.1, where among of these compounds isocorilagin shows best docking score shown in Table 1. The negative and low value of free energy of binding demonstrates a strong favorable bond between 3ERT and isocorilagin in most favourable conformations. The results of docking analysis were described in Table 1 and the docking figure showed in Figures $1 \& 2$.

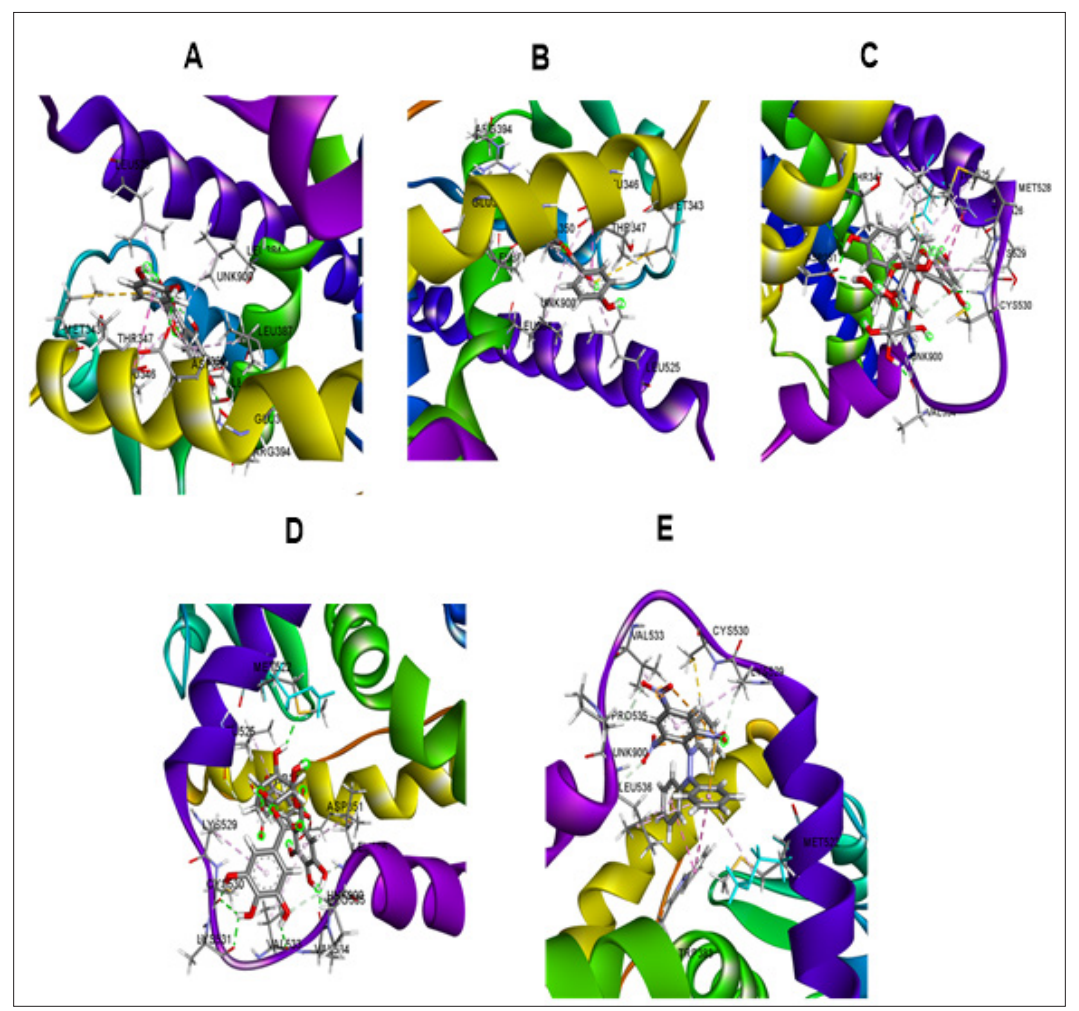

Figure 2: Best ranked pose of quercetin (CID 5280343), kaempferol (CID 5280863), kaempferol 3-bita-D-glucopyranoside (CID 5318761), isocorilagin (CID 10077799) and 1,1-diphenyl-2-picrylhydrazyl (CID 2735032) in the binding pocket of estrogen receptor alpha (PDB: 3ERT).

Table 1: Docking results of quercetin (CID 5280343), kaempferol (CID 5280863), kaempferol 3-bita-D-glucopyranoside (CID 5318761), isocorilagin (CID 10077799) and 1,1-diphenyl-2picrylhydrazyl (CID 2735032) with estrogen receptor alpha (PDB: 3ERT).

\begin{tabular}{|c|c|c|}
\hline Compound Name & Compound ID & Docking Score \\
\hline quercetin & 5280343 & -7.572 \\
\hline kaempferol & 5280863 & -7.665 \\
\hline $\begin{array}{c}\text { kaempferol 3-bita-D- } \\
\text { glucopyranoside }\end{array}$ & 5318761 & -6.77 \\
\hline isocorilagin & 10077799 & -7.901 \\
\hline $\begin{array}{c}\text { 1,1-diphenyl-2- } \\
\text { picrylhydrazyl }\end{array}$ & 2735032 & -5.063 \\
\hline
\end{tabular}

\section{Discussion}

Breast cancer is known as a death sentence and second major cause of death in world. Ratio of breast cancer in is one in nine in case of women [26]. Main cause of breast cancer is over expression of estrogen receptor alpha26.Therefore ER- $\alpha$ is used as a target for prevention of breast cancer. Tamoxifen is an antagonist of ER- $\alpha$ and commercially available as a drug to control the breast cancer [27]. It binds with Arg394 and blocks the function of estrogen receptor and inhibits the function of ER- $\alpha$ [28]. Docking allows the scientist to virtually screen a database of compounds and predict the strongest binders based on various scoring functions. It explores ways in which two molecules, such as drugs and an enzyme Human estrogen receptor fit together and dock to each other well, like pieces of a three-dimensional jigsaw puzzle. The molecules 
binding to a receptor, inhibit its function, and thus act as drug. In recent research, computer aided drug designing (CADD) helps the researcher to decrease the time and money for drug designing projects [29]. Molecular docking is very helpful in studying the interactions of ligand molecules with the target protein before its in vitro synthesis. Docking is performed through computer programs like Maestro.

To screen out the effective bioactive compounds from Phyllanthus emblica namely quercetin, kaempferol, kaempferol 3-bita-D-glucopyranoside, isocorilagin and 1,1-diphenyl-2picrylhydrazyl which may be potential inhibitors of estrogen receptor alpha (ER- $\alpha$ ) for searching a drug against the breast cancer. We performed Glide docking analysis by Schrodinger suite v10.1. A wide range of docking score found during molecular docking. quercetin, kaempferol, kaempferol 3-bita-D-glucopyranoside, isocorilagin and 1,1-diphenyl-2-picrylhydrazyl showed the docking score $-7.572 \mathrm{kj} / \mathrm{mol},-7.665 \mathrm{kj} / \mathrm{mol},-6.77 \mathrm{kj} / \mathrm{mol},-7.901 \mathrm{kj} / \mathrm{mol}$ and $-5.063 \mathrm{kj} / \mathrm{mol}$ respectively. Among of these compounds isocorilagin shows highest docking score shown in Table 1 . The negative and low value of free energy of binding demonstrates a strong favorable bond between 3ERT and isocorilagin in most favourable conformations.

\section{Conclusion}

Among all the compounds isocorilagin showed best docking score towards estrogen receptor alpha. So, isocorilagin is the best compounds for selective inhibitors of estrogen receptor alpha as it possessed best value in Molecular docking. Further in vitro and in vivo investigation need to identify estrogen receptor alpha inhibitory activity of isolated compounds from Phyllanthus emblica.

\section{Acknowledgment}

The authors thank GUSTO (A research group) for providing the software.

\section{References}

1. Orlando G, Pilone V, Vitiello A (2014) Gastric cancer following bariatric surgery: a review. Surg Laparosc Endosc Percutaneous Tech 24(5): 400405.

2. Al-Saleem T (2016) What Is "Cancer." Is There A Need New Terminol.

3. Schram FR, Ng PKL (2012) What is cancer? J Crustac Biol 32(4): 665672.

4. Richardson P (1997) What is cancer? Pract Nurs 8(18): 27-29.

5. McGuire S (2016) World cancer report 2014. Geneva, Switzerland: World Health Organization, international agency for research on cancer WHO Press.

6. Slamon DJ, Clark GM, Wong SG, Levin WJ, Ullrich A, et al. (1987) Human breast cancer: correlation of relapse and survival with amplification of the HER-2/neu oncogene. Science 235(4785): 177-182.

7. Nathanson KN, Wooster R, Weber BL (2001) Breast cancer genetics: what we know and what we need. Nat Med 7(5): 552.

8. Helgeson VS, Cohen S, Schulz R, Yasko J (2000) Group support interventions for women with breast cancer: who benefits from what? Heal Psychol 19(2): 107.
9. Burgess CC, Ramirez AJ, Richards MA, Love SB (1998) Who and what influences delayed presentation in breast cancer? Br J Cancer 77(8): 1343.

10. Joensuu H, Kellokumpu-Lehtinen P-L, Bono P (2006) Adjuvant docetaxel or vinorelbine with or without trastuzumab for breast cancer. $\mathrm{N} \mathrm{Engl} \mathrm{J}$ Med 354(8): 809-820.

11. (1979) Organization WH. WHO handbook for reporting results of cancer treatment.

12. McPherson K, Steel C, Dixon JM (2000) ABC of breast diseases: breast cancer-epidemiology, risk factors, and genetics. BMJ Br Med J 321(7261): 624.

13. Liu X, Zhao M, Wang J, Yang B, Jiang Y, et al. (2008) Antioxidant activity of methanolic extract of emblica fruit (Phyllanthus emblica L.) from six regions in China. J food Compos Anal 21(3): 219-228.

14. Yusuf M, Chowdhury JU, Wahab MA, Begum J (1994) Medicinal plants of Bangladesh. Bangladesh Counc Sci Ind Res Dhaka, Bangladesh p. 192.

15. Ghani A (1998) Medicinal Plants of Bangladesh: Chemical Constituents and Uses. Asiatic society of Bangladesh.

16. Mirunalini S, Krishnaveni M (2010) Therapeutic potential of Phyllanthus emblica (amla): the ayurvedic wonder. J Basic Clin Physiol Pharmacol 21(1): 93-105.

17. Williamson EM (2002) Major Herbs of Ayurveda. Churchill Livingstone.

18. Arun Y, Saranraj K, Balachandran C, Perumal PT (2014) Novel spirooxindole-pyrrolidine compounds: Synthesis, anticancer and molecular docking studies. Eur J Med Chem 74: 50-64.

19. Lu S-H, Wu JW, Liu H-L (2011) The discovery of potential acetylcholinesterase inhibitors: a combination of pharmacophore modeling, virtual screening, and molecular docking studies. J Biomed Sci 18(1): 8.

20. Oshiro C, Bradley EK, Eksterowicz J (2004) Performance of 3D-database molecular docking studies into homology models. J Med Chem 47(3): 764-767.

21. Shoichet BK, McGovern SL, Wei B, Irwin JJ (2002) Lead discovery using molecular docking. Curr Opin Chem Biol 6(4): 439-446.

22. Berman HM, Westbrook J, Feng Z (2000) The protein data bank. Nucleic Acids Res 28(1): 235-242.

23. Shiau AK, Barstad D, Loria PM (1998) The structural basis of estrogen receptor/coactivator recognition and the antagonism of this interaction by tamoxifen. Cell 95(7): 927-937.

24. Halgren TA, Murphy RB, Friesner RA (2004) Glide: a new approach for rapid, accurate docking and scoring. 2. Enrichment factors in database screening. J Med Chem 47(7): 1750-1759.

25. Friesner RA, Banks JL, Murphy RB (2004) Glide: a new approach for rapid, accurate docking and scoring. 1. Method and assessment of docking accuracy. J Med Chem 47(7): 1739-1749.

26. Naeem M, Khan N, Aman Z, Nasir A, Samad A, et al. (2008) Pattern of breast cancer: experience at Lady Reading Hospital, Peshawar. J Ayub Med Coll Abbottabad 20(4): 22-25.

27. Jordan VC (1992) The role of tamoxifen in the treatment and prevention of breast cancer. Curr Probl Cancer 16(3): 134-176.

28. Desai N, Mahto MK, Alekhya B, Naveen CR, Bhaskar M et al. (2012) Comparative docking studies of estrogen receptor inhibitors and their binding interaction analysis. Int J Pharm Sci Rev Res 16(9).

29. Ooms F (2000) Molecular modeling and computer aided drug design. Examples of their applications in medicinal chemistry. Curr Med Chem $7(2): 141-158$. 


\section{ISSN: 2574-1241}

DOI: $10.26717 / B J S T R .2018 .10 .001917$

Nasrin Akther. Biomed J Sci \& Tech Res

(c) (i) This work is licensed under Creative

Submission Link: https://biomedres.us/submit-manuscript.php

$\begin{array}{ll}\text { BIOMEDICAL } & \text { Assets of Publishing with us } \\ \text { RESEARCHES } & \text { - Global archiving of articles } \\ \text { - Immediate, unrestricted online access } & \text { - Rigorous Peer Review Process } \\ \text { https://biomedres.us/ }\end{array}$

